\title{
Caracterização farmacognóstica de folhas de Davilla elliptica St.-Hil. (Dilleniaceae)
}

\author{
M.L. Soares ${ }^{1}$, M.H. Rezende ${ }^{2}$, H.D. Ferreira ${ }^{2}$, A.D.L. Figueiredo ${ }^{1}$, K.G.L. Bustamante ${ }^{1}$, \\ M.T.F. Bara ${ }^{3}$, J.R. Paula ${ }^{3}$ \\ 'Programa de Pós-Graduação em Biologia, Universidade Federal de Goiás, Goiânia, 740001-970, Goiás, Brasil, \\ ${ }^{2}$ Instituto de Ciências Biológicas, Universidade Federal de Goiás, Caixa Postal 131, 740001-970, \\ Goiânia, Goiás, Brasil, \\ ${ }^{3}$ Faculdade de Farmácia, Universidade Federal de Goiás, 74605-220, Goiânia, Goiás, Brasil
}

\begin{abstract}
RESUMO: Davilla elliptica St.-Hil. é empregada popularmente no tratamento de hemorróidas, diarréias e ferimentos. O propósito deste trabalho foi realizar o estudo farmacognóstico de folhas de D. elliptica de dois locais do Estado de Goiás. Cortes paradérmicos e transversais foram submetidos a técnicas usuais de microscopia óptica. As folhas de $D$. elliptica são hipoestomáticas, sendo os estômatos predominantemente paracíticos. $\mathrm{Na}$ epiderme observam-se tricomas unicelulares em ambas faces. O mesofilo é isobilateral e apresenta idioblastos cristalíferos. O sistema vascular na nervura principal é constituído por três feixes vasculares, formando uma estrutura circular. No pecíolo o sistema vascular apresenta uma estrutura circular formada, provavelmente, pela união de vários feixes vasculares. O material pulverizado foi submetido a testes de prospecção fitoquímica, de pureza e quantitativo. Foi constatada a presença de taninos, cumarinas, resinas, flavonóides, saponinas, esteróides e triterpenóides. Os teores de cinzas totais foram de 10,32\% e 12,26\%; os de cinzas insolúveis em ácido, 7,46\% e 9,68\%; e os de umidade, 9,92\% e 9,50\%. Os teores de flavonóides totais foram de $1,20 \%$ e $1,48 \%$, e os de taninos $9,89 \%$ e $13,96 \%$. Devido ao número reduzido de amostras, não é possível afirmar, através deste estudo, que o perfil farmacognóstico de D. elliptica seja influenciado por fatores abióticos.
\end{abstract}

Unitermos: Davilla elliptica, Dilleniaceae, lixeirinha, anatomia foliar, prospecção fitoquímica.

\begin{abstract}
Pharmacognostic characterization of the leaves of Davilla elliptica St.-Hil. (Dilleniaceae)". Davilla elliptica St.-Hil. is popularly used in the treatment of hemorrhoid, diarrhea and wounds. The aim of this work was to characterize pharmacognosticaly two leaves samples of D. elliptica. Paradermal and transversal sections had been submitted the usual techniques of optical microscopy. The leaves of $D$. elliptica are hypostomatics, and the stomata predominantly paracytic. In both epidermis were observed unicellular non-glandular trichomes. The mesophyll is isolateral and shows idioblasts with crystals in raphide. The vascular system in the midrib is constituted by three vascular bundles, forming a circular structure. The petiole shows a circular structure probably formed by union of many vascular bundles localized in the central region. The powdered plant material was submitted to tests of phytochemical prospection, of purity and quantitative. There had been evidenced the presence of tannins, coumarins, resins, flavonoids, saponins and steroids. The content of total ashes was of $10,32 \%$ and $12,26 \%$, insoluble in acid of $7,46 \%$ and $9,68 \%$; the humidity of $9,92 \%$ and $9,50 \%$. The flavonoids contents was of $1,20 \%$ and $1,48 \%$; the tannins contents was of $9,89 \%$ and $13,96 \%$. Because of the reduced number of samples, it was not possible to affirm through this study that the pharmacognostic profile de $D$. elliptica is influenced by abiotics factors.
\end{abstract}

Keywords: Davilla elliptica, Dilleniaceae, lixeirinha, leaves anatomy, phytochemical prospection.

\section{INTRODUÇÃO}

A família Dilleniaceae possui cerca de dez gêneros de ampla distribuição nos trópicos e subtrópicos (Joly, 1993). É constituída por árvores, arbustos e lianas de folhas inteiras, peninérveas, sem estípulas, com filotaxia alterna e geralmente apresentam as células epidérmicas impregnadas de sílica, o que lhes confere certa aspereza ao tato (Barroso et al., 1978). A espécie D. elliptica, um arbusto que atinge $1,5 \mathrm{~m}$ de altura, com folhas de pêlos ásperos, flores amarelas e frutos secos redondos de cor marrom-amarelada, ocorre naturalmente no bioma Cerrado (Silva et al., 2001; Sano; Almeida,1998) e é conhecida popularmente como lixeirinha, lixeira, bugre, sambaibinha e muricizinho.

No Cerrado, além da espécie D. elliptica, o 
gênero Davilla ainda apresenta as espécies D. angustifolia St.-Hil., D. cearensis Huber, D. grandiflora St.-Hil. \& Tul., D. nitida (Vahl.) Kubitzki e D. rugosa Poir. (Sano; Almeida, 1998).

Dados etnobotânicos revelam que determinadas espécies da família Dilleniaceae são empregadas na medicina tradicional com diferentes indicações. Curatella americana L. é empregada como antiinflamatório e antiúlcera (Cronquist, 1981; Corrêa, 1984). D. rugosa Poir. é utilizada como antiinflamatório, antiúlcera, purgativo, estimulante, afrodisíaco e tônico (Le Cointe, 1934; Silva, 1935; Corrêa, 1984). D. elliptica é empregada como adstringente, tônico, laxativo, sedativo, diurético (Rodrigues; Carvalho, 2001), no tratamento de hemorróidas, hérnia e diarréia, e em aplicações tópicas como antisséptico na limpeza de ferimentos (Silva et al., 2001).

Investigações farmacológicas realizadas em ratos, detectaram a atividade anti-ulcerogênica dos extratos hidroalcoólico e aquoso do caule de $D$. rugosa (Guaraldo et al., 2001; Guaraldo, 2001). As atividades antiinflamatória e analgésica foram observadas com o extrato hidroalcoólico da casca de $C$. americana (Moreira et al., 1999). Em relação a D. elliptica, observou-se efeito imunoestimulatório em ratos para os extratos metanólico e etanólico das folhas, o que sugere um benefício no aumento da imunidade contra doenças infecciosas (Carlos et al., 2005).

Com o objetivo de fornecer subsídios farmacognósticos ao controle de qualidade da matériaprima preparada a partir das folhas de D. elliptica, neste trabalho foram realizados o estudo da anatomia e a abordagem fitoquímica de folhas de $D$. elliptica coletadas em dois locais distintos do Estado de Goiás, complementados por testes de pureza e pela avaliação quantitativa de flavonóides e taninos.

\section{MATERIAL E MÉTODOS}

\section{Material botânico}

Para a realização do estudo, foram utilizadas folhas de Davilla elliptica St.-Hil. coletadas no município de Alexânia (16²'52"S e 48²6'47'W, a $855 \mathrm{~m}$ de altitude), e em Goiânia, em terreno baldio no Jardim Itanhangá (16³4'04'S e 49¹7'08'W, a 766m de altitude), respectivamente em abril e em julho de 2003.

O material botânico foi identificado pelo Prof. Dr. José Realino de Paula, da Universidade Federal de Goiás, e as exsicatas encontram-se depositadas no Herbário desta instituição, sob registro UFG/27529 e $\mathrm{UFG} / 27530$, respectivamente.

\section{Descrição microscópica}

Para a caracterização microscópica foram realizadas análises de secções transversais do pecíolo (região mediana) e da lâmina foliar (segmentos da nervura principal, região internervural e bordo) e paradérmicas das faces adaxial e abaxial da lâmina foliar.

Os cortes histológicos, realizados à mão livre, a partir de material botânico fresco e fixado em FPA 70 e conservado em álcool etílico a $70 \%$, foram clarificados com hipoclorito de sódio a $30 \%$, lavados com água destilada e submetidos ao processo de dupla coloração Azul de alcian / safranina 9:1 e aos reagentes de Steinmetz (Kraus; Arduin, 1997) e de Etzold (Etzold, 1993). Para a contagem estomática da região mediana da folha, fragmentos foliares de $1 \mathrm{~cm}^{2}$ foram submetidos à mistura de Jeffrey para o destacamento das epidermes, posteriormente tratadas com Azul de alcian / safranina 9:1 (Kraus; Arduin, 1997). O número de estômatos por $\mathrm{mm}^{2}$ foi determinado conforme técnica de Laboriau et al. (1961).

A análise microscópica do pó foi realizada empregando-se os reagentes de Steinmetz (Costa, 1982) e de Etzold (Etzold, 1993).

O registro fotográfico das estruturas anatômicas foi feito em fotomicroscópio (ZEISS-AXIOSKOP), utilizando-se filme Kodacolor, ASA 100. Para o reconhecimento de constituintes celulares de natureza cristalina os cortes histológicos foram submetidos à luz polarizada. As escalas referentes às ilustrações foram obtidas nas mesmas condições ópticas.

\section{Prospecção fitoquímica}

O material botânico foi seco em estufa de circulação de ar, a $40^{\circ} \mathrm{C}$, e moído em moinho de facas para a realização das análises fitoquímicas. A pesquisa dos metabólitos secundários foi realizada através de testes de prospecção fitoquímica de acordo com metodologias adaptadas de Costa (1982), Matos (1988), e Matos e Matos (1989). Os constituintes do metabolismo secundário pesquisados foram: antraquinonas, esteróides e triterpenóides, heterosídeos flavonóides, heterosídeos saponínicos, taninos, alcalóides, cumarinas e resinas.

\section{Testes de pureza}

A partir do material botânico pulverizado, foram determinados os teores de cinzas totais, insolúveis em ácido, e a umidade. Os ensaios para a determinação desses parâmetros de qualidade foram realizados em triplicata, conforme técnica adaptada da Farmacopéia Brasileira (1988).

\section{Testes quantitativos}

Com base nos resultados obtidos na prospecção fitoquímica foram realizados os doseamentos de flavonóides (Farmacopéia Brasileira, 2002) e taninos totais (Waterman; Mole, 1994), com três repetições para cada amostra. 

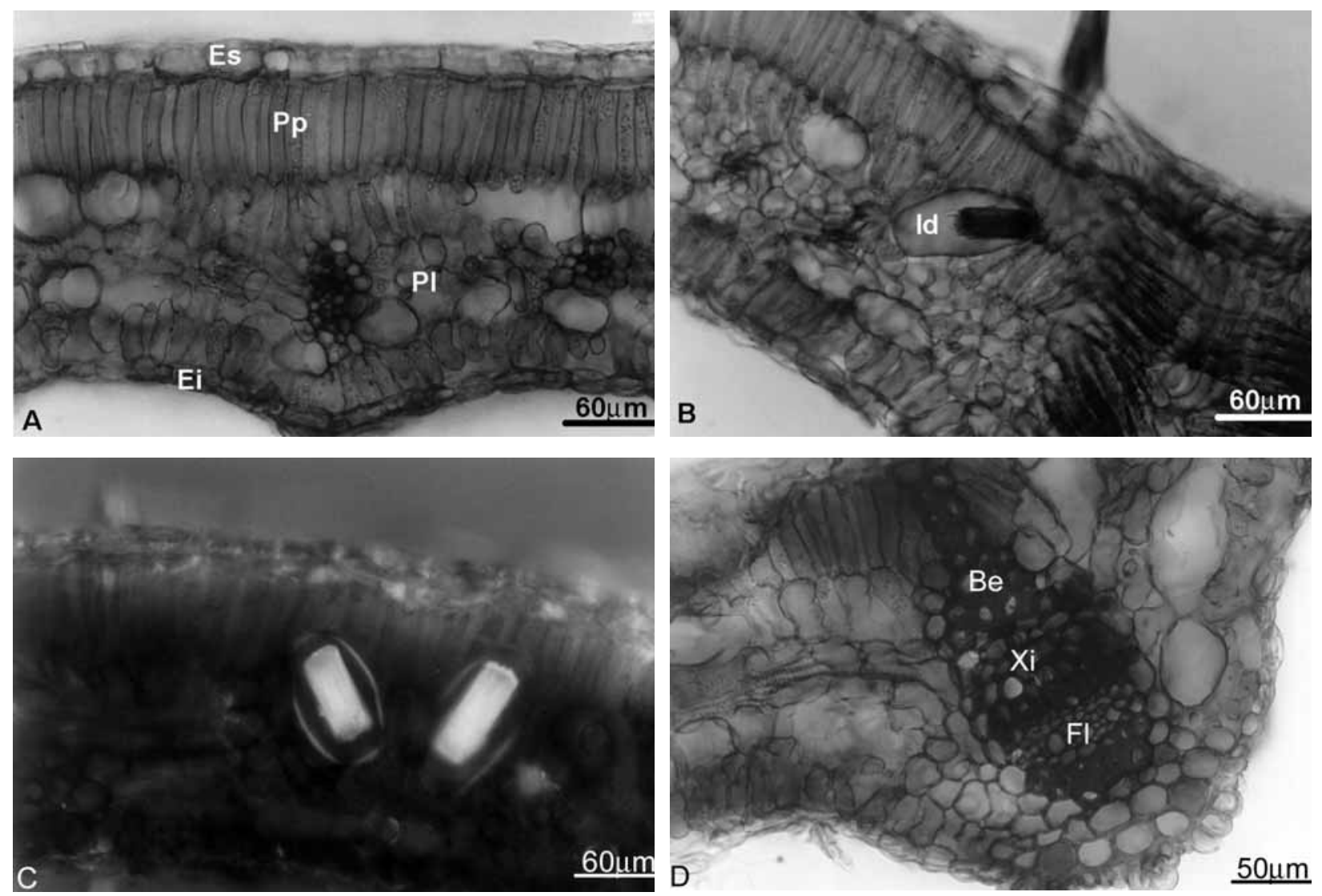

Figuras 1A - 1D. Davilla elliptica St. -Hil. Dilleniaceae. Secção transversal da lâmina foliar.

$1 \mathrm{~A}$ - Epidermes superior e inferior unisseriadas e mesofilo isolateral. Es - epiderme superior,

Ei - epiderme inferior, Pp - parênquima paliçádico, $\mathrm{Pl}$ - parênquima lacunoso.

1B - Idioblasto com cristais em forma de ráfide. Id - idioblasto.

$1 \mathrm{C}$ - Detalhe de cristais em luz polarizada.

1D - Detalhe de feixe vascular secundário do tipo colateral. Be - bainha esclerenquimática, Xi - xilema, Fl - floema.

\section{RESULTADOS}

\section{Descrição microscópica}

Olimbo, em secção transversal, apresenta epiderme unisseriada nas faces adaxial e abaxial. O mesofilo é isobilateral, sendo que na face adaxial o parênquima paliçádico é contínuo e, predominantemente, unisseriado, apresentando-se bisseriado em pequenas extensões (Figura 1A). Na face abaxial, no entanto, o parênquima paliçádico é descontínuo e unisseriado (Figuras 1A e 1B). $\mathrm{O}$ parênquima esponjoso ocupa aproximadamente $1 / 3$ do mesofilo (Figura 1A). Foram registrados idioblastos contendo cristais em forma de ráfides (Figuras 1B e 1C), assim como feixes vasculares secundários do tipo colateral com extensão de bainha esclerenquimática em direção à epiderme adaxial (Figura 1C).

Anervura principal seccionada transversalmente, apresenta a epiderme unisseriada com tricomas tectores unicelulares longos e curtos em ambas as faces (Figura
2A). A epiderme é acompanhada por até três camadas de células colenquimáticas (Figuras 2A e 2C). No córtex nota-se a presença de esclereídes (Figura 2C), e o parênquima cortical é constituído por células de tamanhos variados (Figuras 2A e 2C). O sistema vascular é constituído por três feixes vasculares, formando uma estrutura circular. O floema posiciona-se externamente ao xilema e é envolvido por uma bainha esclerenquimática. A região central do sistema vascular é preenchida por parênquima medular (Figuras 2A e 2B).

A região mediana do pecíolo em secção transversal, apresenta epiderme unisseriada com tricomas tectores unicelulares longos e curtos nas duas faces (Figura 3A). Sob a epiderme ocorre colênquima contendo até quatro camadas de células (Figuras 3A e 3D). O parênquima cortical é constituído por células de paredes delgadas com formatos e tamanhos variados (Figura 3D). $\mathrm{Na}$ região cortical foram registradas esclereídes (Figuras $3 \mathrm{C}$ e 3D). O sistema vascular apresenta estrutura circular formada, provavelmente, pela união de vários feixes vasculares. O floema encontra-se externamente ao xilema 

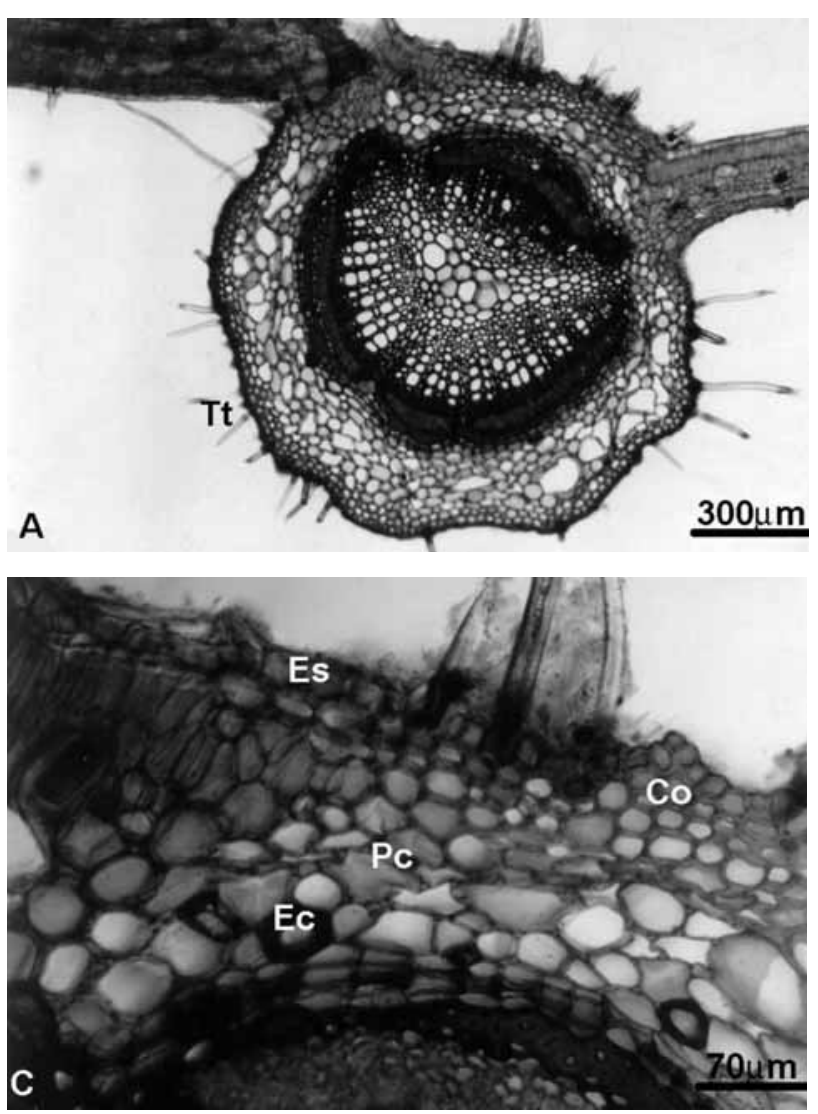

Figuras 2A - 2C. Davilla elliptica St. -Hil. Dilleniaceae. Secção transversal da nervura principal.

2A - Aspecto geral da nervura principal. $\mathrm{Tt}$ - tricoma tector.

2B - Detalhe do sistema vascular. Be - bainha esclerenquimática, Xi - xilema, Fl - floema, Pm parênquima medular.

2C - Detalhe da face adaxial. Es - epiderme superior, Co colênquima, $\mathrm{Pc}$ - parênquima cortical, Ec-esclereíde.

e envolvido por uma bainha esclerenquimática, assim como na nervura principal da lâmina foliar (Figuras 3A e 3B). Lateralmente, na superfície adaxial, observam-se dois pequenos feixes colaterais (Figuras 3A - 3C). A área medular é preenchida por tecido parenquimático (Figuras $3 \mathrm{~A}$ e $3 \mathrm{~B})$.

A organização anatômica observada no bordo da lâmina foliar apresenta o mesmo aspecto nas regiões basal, mediana e apical. A epiderme é unisseriada formada por células menores e cutícula mais espessa em relação à epiderme das outras regiões da lâmina foliar. Entre a epiderme e o último feixe vascular observa-se colênquima (Figura 4). O feixe vascular é colateral e encontra-se envolvido por uma bainha parenquimática.

A lâmina foliar, em vista frontal, exibe tricomas tectores unicelulares e lignificados em ambas as faces, principalmente sobre as nervuras da face abaxial. Na epiderme da face adaxial, observam-se células de tamanhos variados, com paredes espessas e contorno

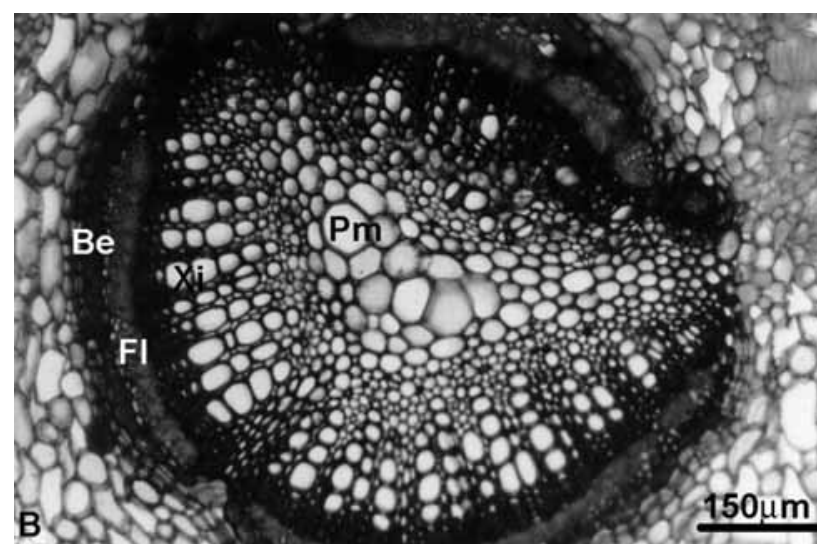

reto a levemente sinuoso. Nos pontos de inserção dos tricomas, as células encontram-se dispostas circularmente (Figura 5A). Na face abaxial, verificam-se células epidérmicas de contorno ondeado a sinuoso e estômatos predominantemente paracíticos (Figura 5B), com ocorrência de estômatos anomocíticos. A região mediana da folha apresenta, em média, 416 estômatos por $\mathrm{mm}^{2}$.

$\mathrm{Na}$ microscopia do pó observaram-se fragmentos de epiderme abaxial, com estômatos e tricomas tectores unicelulares, e de feixes vasculares, e cristais em forma de ráfide (Figuras 6A-6D).

\section{Prospecção fitoquímica}

$\mathrm{Na}$ pesquisa de metabólitos secundários foi detectada a presença de heterosídeos flavonóides e saponínicos, esteróides, triterpenóides, taninos, cumarinas e resinas, em ambas as amostras.

\section{Testes de pureza}

A amostra de D. elliptica coletada em Alexânia apresentou teor de cinzas totais e de cinzas insolúveis em ácido igual a $10,32 \%$ e $7,46 \%$, respectivamente, e o teor de umidade foi de $9,92 \%$. Na amostra coletada em Goiânia observou-se um teor de cinzas totais igual a $12,26 \%$ e de cinzas insolúveis em ácido igual a 9,68\%, e o teor de umidade apresentado foi de $9,50 \%$.

\section{Testes quantitativos}

O teor de flavonóides totais observado foi de $1,20 \%$ para a amostra coletada em Alexânia, e de 1,48\% para a amostra coletada em Goiânia.

$\mathrm{O}$ teor de taninos totais verificado na amostra coletada em Alexânia foi de 9,89\%, e de 13,96\% na amostra coletada em Goiânia.

\section{DISCUSSÃO}

Descrição microscópica 


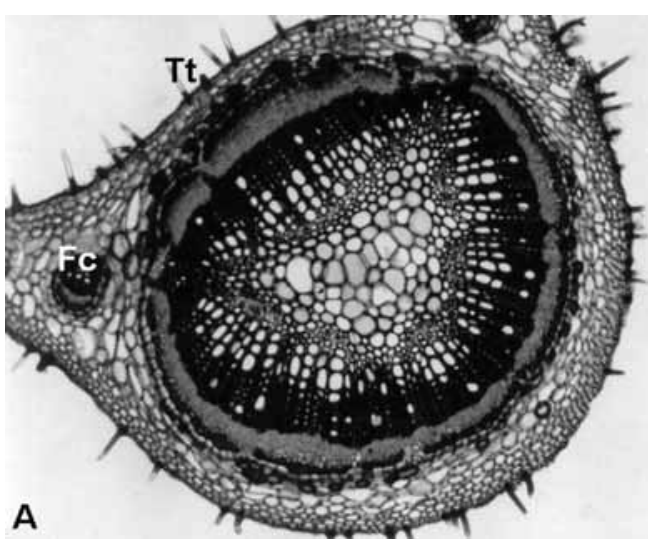

$\underline{300 u m}$

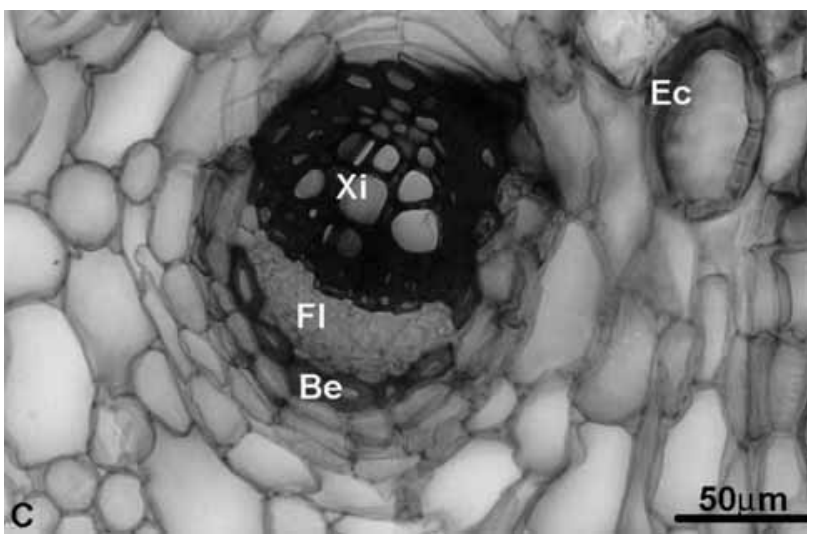

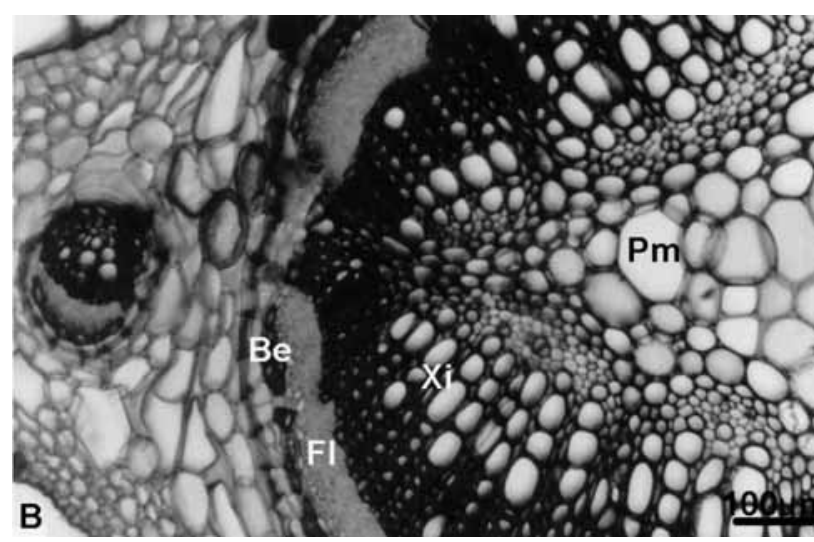

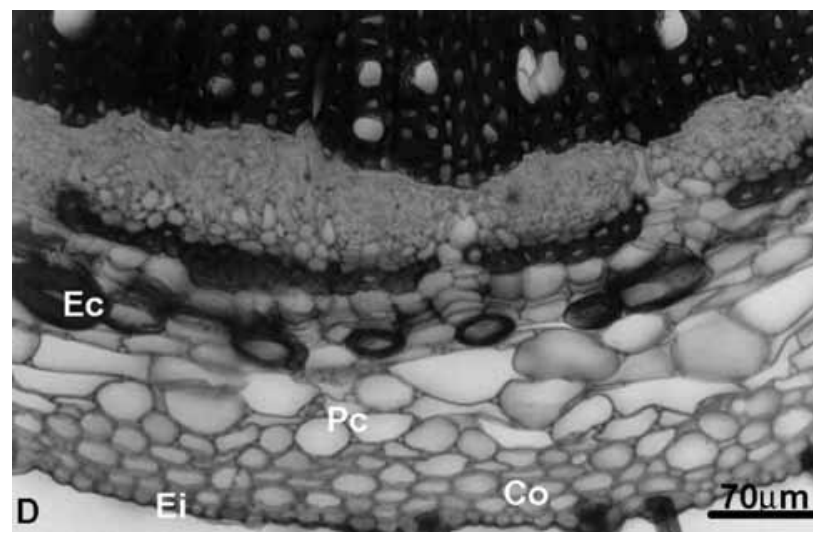

Figuras 3A - 3D. Davilla elliptica St. -Hil. Dilleniaceae. Secção transversal do pecíolo.

$3 \mathrm{~A}$ - Aspecto geral do pecíolo. Tt - tricoma tector, $\mathrm{Fc}$ - feixe vascular colateral.

3B - Detalhe do sistema vascular. Be - bainha esclerenquimática, Xi - xilema, Fl - floema, Pm - parênquima medular.

3C - Detalhe do feixe vascular lateral. Be - bainha esclerenquimática, Xi - xilema, Fl - floema, Ec - esclereíde.

3D - Detalhe da face abaxial. Ei - epiderme inferior, Co - colênquima, Pc - parênquima cortical, Ec - esclereíde.

O presente trabalho revelou que as folhas de Davilla elliptica St.-Hil. apresentam determinados caracteres anatômicos comuns aos descritos anteriormente na literatura especializada para a família Dilleniaceae. Entre estes, a presença de estômatos apenas na superfície abaxial da lâmina foliar, de esclereídes no parênquima cortical do pecíolo (Dickison, 1970) e de cristais em forma de ráfide (Cronquist, 1968).

$\mathrm{Na}$ análise anatômica da folha de $D$. elliptica foram registradas características que corroboram os dados apresentados por Oliveira e Castro (2002), bem como a presença de idioblastos com cristais em forma de ráfide no mesofilo; parênquima paliçádico situado sob a epiderme adaxial de forma bisseriada em determinadas regiões; estômatos predominantemente paracíticos, com ocorrência de estômatos anomocíticos, e a média de 416 estômatos por $\mathrm{mm}^{2}$ na região mediana da lâmina foliar.

O número médio de estômatos por $\mathrm{mm}^{2}$ registrado para D. elliptica constitui uma característica xeromórfica. Conforme Fahn e Cutler (1992), a densidade máxima de estômatos em espécies desérticas é de 415 estômatos por $\mathrm{mm}^{2}$. Segundo Lleras (1977), quanto mais xerofíticas as condições, maior é a freqüência estomática por unidade de área, o que permite trocas gasosas mais eficientes quando a umidade relativa do ar é alta. No entanto, de acordo com Esau (1977), o número de estômatos por unidade de superfície é tão variável que possui pouco valor taxonômico.

Segundo Medri e Lleras (1980), a leve sinuosidade das paredes das células epidérmicas constitui um caráter adaptativo contra a perda excessiva de água. Esta característica foi registrada nas células da epiderme adaxial em folhas de D. elliptica, sendo justificada pelo fato de ser a face mais exposta à radiação solar.

$\mathrm{Na}$ espécie em estudo foram registrados tricomas em ambas as faces da lâmina foliar, particularmente sobre as nervuras. Os tricomas são anexos epidérmicos que reduzem a transpiração ao produzirem uma camada de ar parado que retém vapor (Fahn, 1986; Ricklefs, 1993). Além disso, nas folhas de muitas espécies do cerrado comumente se observam tricomas localizados sobre as células epidérmicas que revestem o sistema condutor, levantando a hipótese de uma possível relação destes tricomas com o mecanismo de absorção de água (Morretes, 1969; Morretes, 1980).

\section{Prospeç̧ão fitoquímica}




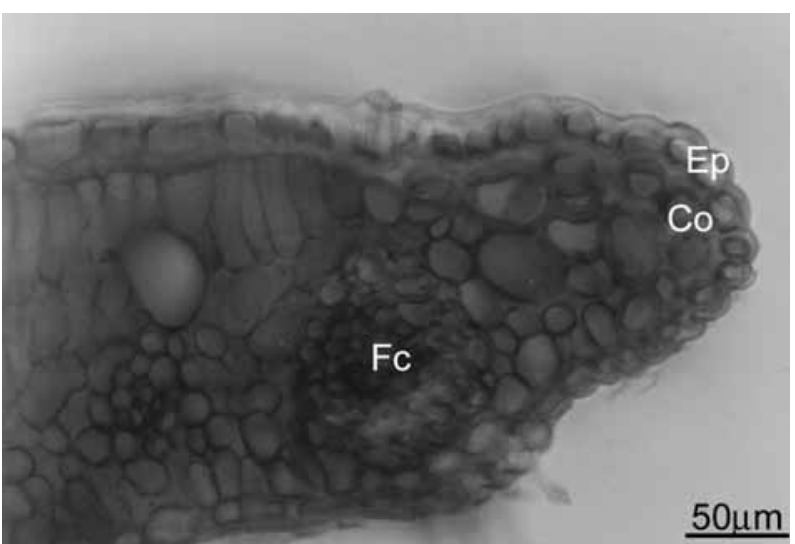

Figura 4. Davilla elliptica St. -Hil. Dilleniaceae. Secção transversal do bordo na região basal da lâmina foliar. Ep epiderme, Co - colênquima, $\mathrm{Fc}$ - feixe vascular colateral.

Conforme Carlos et al. (2005), nos extratos metanólico e etanólico da folha de D. elliptica foram pesquisados flavonóides, triterpenóides, esteróides, alcalóides, antraquinonas, ácido gálico, catequinas, taninos, saponinas e cumarinas. Foram positivos os testes para flavonóides, triterpenóides, esteróides, ácido gálico e catequinas. A triagem fitoquímica da folha de $D$. elliptica realizada neste trabalho, apresentou resultados que corroboram apenas parcialmente os resultados apresentados por Carlos et al. (2005), devido a detecção de taninos, saponinas e cumarinas. Segundo Guaraldo et al. (2001), em caule de D. rugosa foram realizados testes para mucilagem, saponinas, flavonóides, alcalóides, antraquinonas, glicosídeos cardíacos e taninos, sendo que as reações para flavonóides, saponinas e mucilagem foram positivas. El-Azizi et al. (1980) afirma que a presença de flavonóides, terpenos, fenóis, saponinas e esteróides é comumente constatada em espécies de Dilleniaceae, como Curatella americana.

Nos extratos metanólico e etanólico da folha de D. elliptica foram observados flavonóides derivados da

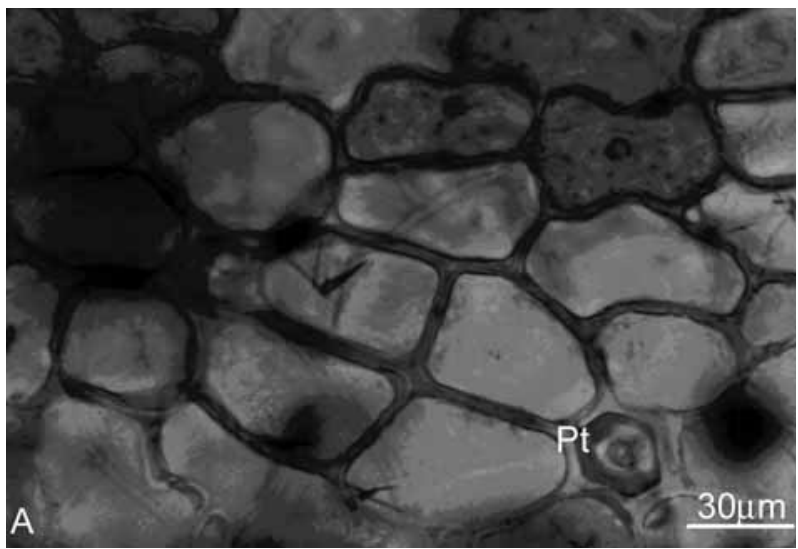

miricetina e da quercetina (Carlos et al., 2005). Em folhas de $D$. rugosa foram isolados

os flavonóides miricetina, miricetina-3-rhamnoside, quercetina, quercetina-3-rhamnoside e caempferol (Gurni; Kubtzki, 1981), o que, segundo David et al. (1996) também tem sido encontrado em outras espécies de Davilla. O alcalóide cafeína foi isolado da semente de D. rugosa (Freise, 1935).

Os resultados desta pesquisa fitoquímica indicaram que não há uma variação qualitativa dos metabólitos secundários pesquisados no material botânico coletado nos dois diferentes locais.

\section{Testes de pureza}

A determinação do teor de cinzas totais permite a verificação de impurezas inorgânicas não-voláteis que podem estar presentes como contaminantes (Farias, 2003), assim como a determinação do teor de cinzas insolúveis em ácido destina-se à verificação da presença de sílica e constituintes silicosos da droga (Farmacopéia Brasileira, 1988). Logo, essas determinações constituem referências de qualidade e caracterização da matéria-prima vegetal.

Conforme Almeida et al. (1998), a aspereza característica das folhas de $C$. americana deve-se ao alto teor de sílica presente neste órgão, o que corrobora a afirmação de Barroso et al. (1978) de que a presença de sílica nas células epidérmicas é uma característica da família Dilleniaceae. De acordo com Netto et al. (2002), os teores de cinzas insolúveis em ácido para duas amostras de folhas de C. americana foram $4,77 \%$ e 5,29\%. Assim, comparando-se os resultados obtidos na determinação do teor de cinzas insolúveis em ácido de $D$. elliptica $(7,46 \%$ e 9,68\%) com os de C. americana, pode-se inferir que o alto teor de sílica presente em amostras foliares seja uma importante característica farmacognóstica destas duas espécies de Dilleniaceae.

$\mathrm{O}$ excesso de umidade em matérias-primas vegetais permite a ação de enzimas, podendo acarretar

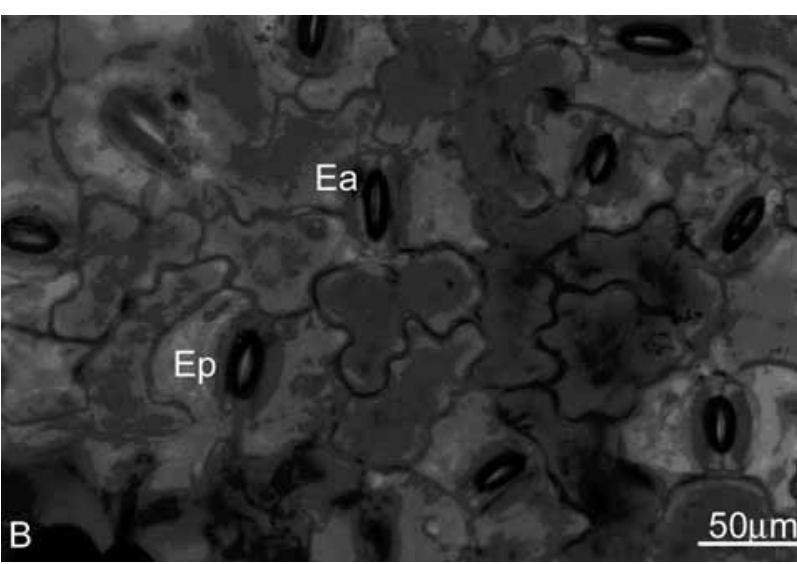

Figuras 5A - 5B. Davilla elliptica St. -Hil. Dilleniaceae. Secção paradérmica da lâmina foliar.

$5 \mathrm{~A}$ - Células epidérmicas de paredes espessadas na face adaxial. Pt - ponto de inserção de tricomas.

5B - Células epidérmicas de contorno ondeado a sinuoso e estômatos paracítico e anomocítico na face abaxial. Ep - estômato paracítico, Ea - estômato anomocítico. 

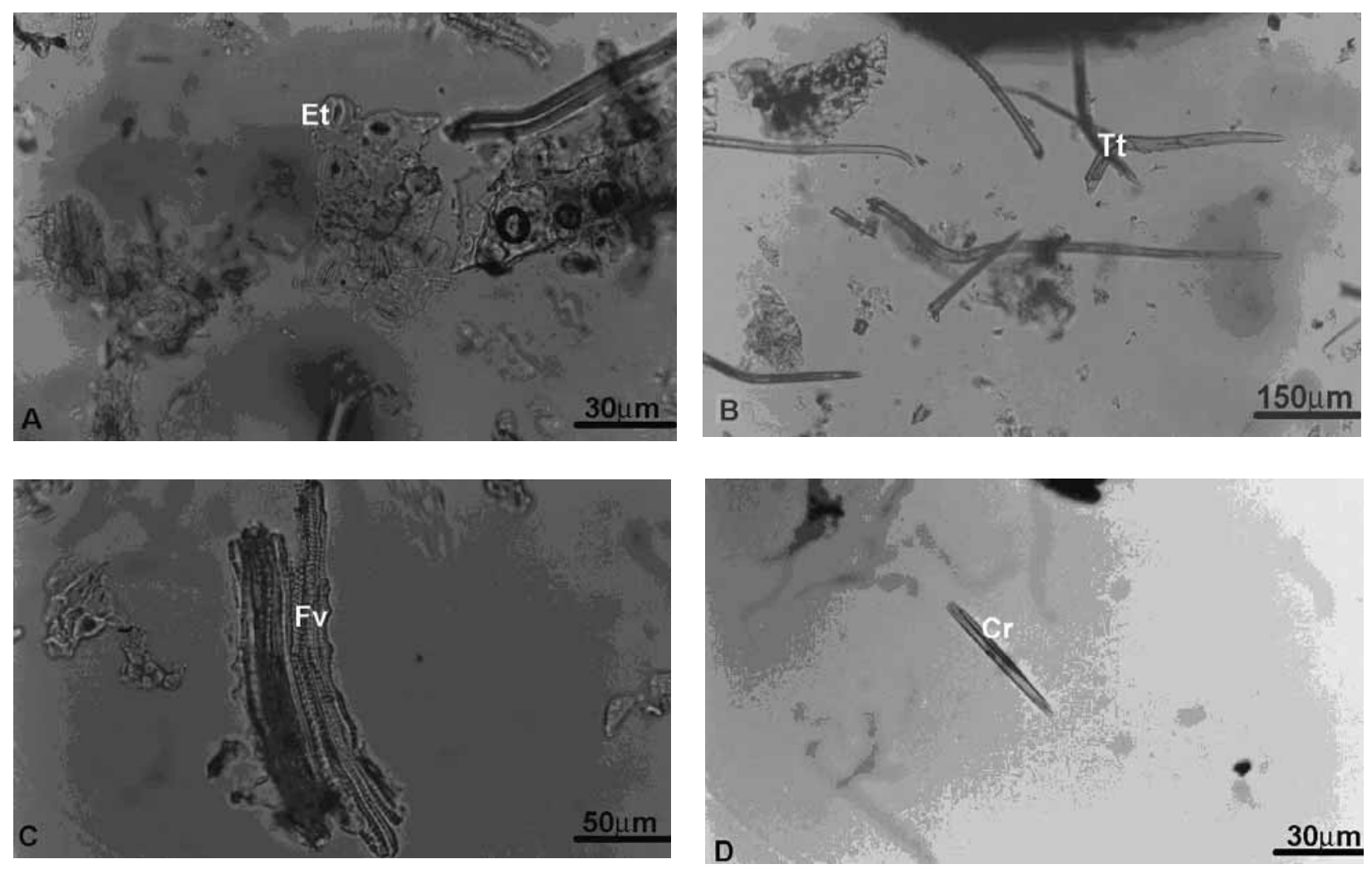

Figuras 6A - 6D. Davilla elliptica St. -Hil. Dilleniaceae. Microscopia do pó.

6A - Fragmentos de epiderme com estômato. Et - estômato.

6B - Fragmentos de epiderme com tricoma tector. Tt - tricoma tector.

$6 \mathrm{C}$ - Fragmentos de feixes vasculares. Fv - feixe vascular.

$6 \mathrm{D}$ - Cristais em forma de ráfide. $\mathrm{Cr}$ - cristal em ráfide.

a degradação de constituintes químicos e possibilitar o desenvolvimento de fungos e bactérias. Portanto, assim como a determinação do teor de cinzas totais e do teor de cinzas insolúveis em ácido, a determinação do teor de umidade também constitui um parâmetro para o controle de qualidade da droga vegetal (Farias, 2003).

$\mathrm{O}$ teor máximo de umidade estabelecido nas diferentes farmacopéias varia entre $8 \%$ e $14 \%$, com poucas exceções especificadas nas monografias (Farias, 2003). Os teores de umidade verificados nas amostras analisadas de D. elliptica $(9,92 \%$ e $9,50 \%)$, portanto, encontram-se dentro dessa faixa de variação.

\section{Testes quantitativos}

Os teores de flavonóides totais verificados nas amostras de folhas de D. elliptica $(1,20 \%$ e $1,48 \%)$ podem ser considerados expressivos, visto que espécies como Ginkgo biloba L. (Ginkgoaceae) e Calendula officinalis L. (Asteraceae), que apresentam teor de flavonóides respectivamente igual a $0,5 \%$ e $0,4 \%$, são drogas vegetais empregadas em terapêtica com teor significativo de flavonóides (OMS, 1999; Farmacopéia Brasileira, 2002; Zuanazzi e Montanha, 2003).

Em relação ao doseamento de taninos totais, comparando-se os resultados obtidos com dados descritos na literatura para outras espécies (Trugilho et al., 2002; Santos; Mello, 2003), pode-se considerar relevantes os teores apresentados pelas amostras de D. elliptica $(9,89 \%$ e $13,96 \%)$, uma vez que espécies conhecidas pelos seus teores elevados de taninos apresentam, no máximo, cerca de $20 \%$ de taninos totais. É o caso, por exemplo, de Stryphnodendron adstringens (Mart.) Coville (barbatimão: 20\%), Potentilla erecta L. Raeusch (tormentila: 15 a 22\%), Psidium guajava L. (goiabeira: 13 a 17\%) e Psidium rufum DC (araçá-pitanga: 20\%).

\section{CONCLUSÃO}

Os resultados da descrição microscópica das folhas de D. elliptica, assim como os resultados obtidos na prospecção fitoquímica, nos testes de pureza e quantitativos, forneceram parâmetros padrões que poderão ser utilizados no controle de qualidade de amostras de folhas de D. elliptica que possam vir a ser comercializadas futuramente.

Como neste estudo foi analisado um número reduzido de amostras de folhas de $D$. elliptica, não foi possível a aplicação de testes estatísticos para verificar se as diferenças observadas entre os resultados dos testes de 
pureza, dos teores de taninos totais e flavonóides totais são significativas. Portanto, não é possível afirmar através destes resultados, que o perfil farmacognóstico de $D$. elliptica seja influenciado por fatores abióticos, tais como condições edáficas, clima, radiação solar, entre outros. Assim, faz-se necessário a observação de um número maior de amostras em trabalhos futuros.

\section{AGRADECIMENTOS}

Agradecemos a CAPES pela concessão de bolsa de mestrado a Marília Luz Soares, a Fundação de Apoio à Pesquisa (FUNAPE/UFG) e a Faculdade de Farmácia/ UFG.

\section{REFERÊNCIAS}

Almeida SP, Proença CEB, Sano SM, Ribeiro JF 1998. Cerrado: espécies vegetais úteis. Planaltina/DF: EMBRAPACAPC.

Barroso GM, Guimarães EF, Ichaso CLF, Costa CG, Peixoto AL 1978. Sistemática das Angiospermas. Rio de Janeiro: Ed. USP.

Carlos IZ, Lopes FCM, Benzatti FP, Carli CBA, Marques MF, Jordão Jr. CM, Rinaldo D, Calvo TR, Santos LC, Vilegas W 2005. Ação do extrato metanólico e etanólico de Davilla elliptica St. Hill. (Dilleniaceae) na resposta imune. Rev Bras Farmacog 15: 44-50.

Corrêa MP 1984. Dicionário das plantas úteis do Brasil e das exóticas cultivadas. Rio de Janeiro: Imprensa Nacional.

Costa AF 1982. Farmacognosia. Lisboa: Fundação Calouste Gulbenkian.

Cronquist A 1968. The evolution and classification of flowering plants. Boston: Hoglton Mifflin Co.

Cronquist A 1981. An integrated system of classification of flowering plants. New York: Columbia University.

David JM, Cruz FG, Guedes MLS, Chavez JP 1996. Flavonol glycosides from Davilla flexuosa. J Braz Chem Soc 7: $115-118$.

Dickison WC 1970. Comparative morphological studies in Dilleniaceae V: Leaf Anatomy. J Arn Arb 51: 89101.

El-Azizi MM, Ateya AM, Svolvoda GH, Schiff Jr. PL, Slatkin DJ, Knapp JE 1980. Chemical Constituints of Curatella americana (Dilleniaceae). J Pharma Sci 69: 360-361.

Esau K 1977. Anatomy of seed plants. New York: John Wileys and Sons.

Etzold H 1993. Eine kontrastreiche simultane mehrfachfärbung für pflanzenanatomische präparate. Mikrokosmos 72: 213-218.

Fahn A 1986. Structural and functional properties of trichomes of xeromorphic leaves. Annals of Botany 57: 631637.

Fahn A, Cutler D 1992. Xerophytes. Berlim: Gebruder Borntraeger.

Farias MR. Avaliação da qualidade de matérias-primas vegetais. In: Simões CMO, Schenkel EP, Gosmann G, Mello JCP, Mentz LA, Petrovick PR. (Org.) 2003. Farmacognosia da Planta ao Medicamento. Porto
Alegre/Florianópolis: UFRGS/UFSC, p. 263-288.

Farmacopéia Brasileira 1988. São Paulo: Atheneu, v. 1.

Farmacopéia Brasileira 2002. São Paulo: Atheneu, v. 2.

Freise FW 1935. Das Vorkommen von koffein in brasilianischen Heilplanzen. Pharmazeutische Zentralhalle fur Deutschland, 76: 704-706.

Guaraldo L 2001. Atividade antiúlcera gástrica do extrato aquoso e frações isoladas de Davilla rugosa Poiret: avaliação dos mecanismos envolvidos. São Paulo. Tese de Doutorado - Escola Paulista de Medicina, Universidade Federal de São Paulo.

Guaraldo L, Sertiè JAA, Bacchi EM 2001. Antiulcer action of the hydroalcoholic extract and fractions of Davilla rugosa Poiret in the rat. J Ethnopharmacol, 76: 191-195.

Gurni AA, Kubtzki K 1981. Flavonoid chemistry and systematics of the Dilleniaceae. Biochem Syst Ecol 9: 09-114.

Joly AB 1993. Botânica: Introdução à taxonomia vegetal. São Paulo: Editora Nacional.

Kraus JE, Arduin M 1997. Manual básico de métodos em morfologia vegetal. Seropédica/RJ:EDUR.

Laboriau LC, Oliveira JC, Laboriau FMLS 1961. Transpiração de Schizolobium parahyba (Vell.) Veloso. An Acad Bras Cienc 33: 248-251.

Le Cointe P 1934. A Amazônia brasileira. Vol. 3. Belém: Livraria Clássica.

Lleras E 1977. Differencies in stomatal number per unit area within the some species under different microenviromental conditions: a working hypothesis. Acta Amazonica 4: 473-476.

Matos FJA 1988. Introdução à fitoquímica experimental. Fortaleza/CE: Edições UFC.

Matos JMD, Matos ME 1989. Farmacognosia. Fortaleza/CE: Edições UFC.

Medri ME, Lleras E 1980. Aspectos da anatomia ecológica de folhas de Hevea brasiliensis Muell. Acta Amazonica 10: 463-493.

Moreira MSA, Piuvezam MR, Araújo CC, Thomas G 1999. Studies on the anti-inflammatory and analgesic activity of Curatella americana L.JEthnopharmacol 67: 171-177.

Morretes BL 1969. Contribuição ao estudo da anatomia das folhas de plantas do Cerrado III. Bol Fac Filos Letr - USP, Botânica, v.24, 331: 7-32.

Morretes BL 1980. Contribuição ao conhecimento da anatomia ecológica de plantas do cerrado de Emas - SP e da caatinga amazônica do Km 62 da Rodovia BR-174. São Paulo, 157p. Tese (Livre Docência) - Instituto de Biociências, Universidade de São Paulo.

Netto HJCB, Souza HPD, Araújo LG 2002. Estudo morfoanatômico e prospecção fitoquímica de Curatella americana L. Goiânia, 46p. Trabalho de Conclusão de Curso (Bacharelado) - Faculdade de Farmácia, Universidade Federal de Goiás.

Oliveira LA, Castro NM 2002. Ocorrência de sílica em Curatella americana L. e Davilla elliptica St.-Hil. Revista Eletrônica Horizonte Científico 1. Disponível em: http://www.propp.ufu.br/revistaeletronica/index/ html. Acesso em: 08 de setembro de 2004.

OMS. 1999. Who monographs on selected medicinal plants. Geneva: World Heath Organization.

Ricklefs RE 1993. A economia da natureza. Rio de Janeiro: Guanabara Koogan. 
Rodrigues VEG, Carvalho DA 2001. Plantas medicinais no domínio dos cerrados. Lavras/MG: UFLA.

Sano SM, Almeida SP 1998. Cerrado ambiente e flora. Planaltina/DF: EMBRAPA-CAPC.

Santos SC, Mello JCP. Taninos. In: Simões CMO, Schenkel EP, Gosmann G, Mello JCP, Mentz LA, Petrovick PR (Org.) 2003. Farmacognosia da planta ao medicamento. Porto Alegre/Florianópolis: UFRGS/ UFSC, p. 615-656.

Silva RAD 1935. Plantas medicinais do Brasil - "Cipó caboclo". Revista da Flora Medicinal 2: 69-78.

Silva SR, Silva AP, Munhoz CB, Silva Jr MC, Medeiros MB (Org.) 2001. Guia de plantas do cerrado utilizadas na Chapada dos Veadeiros. Brasília/DF: WWF.

Trugilho PF, Caixeta RP, Lima JT, Mendes LM 2002. Avaliação do conteúdo de taninos condensados de algumas espécies típicas do cerrado mineiro. Disponível em: http://www.dcf.ufla.br/ceme/revista, v. 3, n.1, 1997. Acesso em: 05 de janeiro de 2003.

Waterman PG, Mole S 1994. Methods in ecology: analysis of phenolic plant metabolites. Victoria/Australia: Blackwell Scientific Publicatios.

Zuanazzi JAZ, Montanha JA. 2003. Flavonóides. In: Simões CMO, Schenkel EP, Gosmann G, Mello JCP, Mentz LA, Petrovick PR (Org.). Farmacognosia da planta ao medicamento. Porto Alegre/Florianópolis: UFRGS/UFSC, p. 576-614. 